\title{
The Effect of Shortfall as a Risk Measure for Portfolios with Hedge Funds
}

\author{
André lucas and Arjen Siegmann*
}

\begin{abstract}
Current research suggests that the large downside risk in hedge fund returns disqualifies the variance as an appropriate risk measure. For example, one can easily construct portfolios with nonlinear pay-offs that have both a high Sharpe ratio and a high downside risk. This paper examines the consequences of shortfall-based risk measures in the context of portfolio optimization. In contrast to popular belief, we show that negative skewness for optimal meanshortfall portfolios can be much greater than for mean-variance portfolios. Using empirical hedge fund return data we show that the optimal mean-shortfall portfolio substantially reduces the probability of small shortfalls at the expense of an increased extreme crash probability. We explain this by proving analytically under what conditions short-put payoffs are optimal for a mean-shortfall investor. Finally, we show that quadratic shortfall or semivariance is less prone to these problems. This suggests that the precise choice of the downside risk measure is highly relevant for optimal portfolio construction under loss averse preferences.
\end{abstract}

Keywords: hedge funds, portfolio optimization, downside risk, expected shortfall

\section{INTRODUCTION}

This paper addresses the choice of an adequate downside risk measure for optimal portfolio construction involving hedge funds. Witnessing the ever-increasing capital invested in hedge funds worldwide, academics, practitioners, and policy makers alike spend time and effort in uncovering the sources and risks of hedge fund returns. Given the opacity of the hedge fund industry, this is not a trivial task. Some of the criticism on hedge funds focuses on the claim that these funds generate a 'peso problem': steady returns may be off-set by occasional crashes. This is evidenced by a substantial negative skewness in hedge fund returns, see for example, Brown, Goetzmann and Park (1997), Brown, Goetzmann and Ibbotson (1999), Brooks and Kat (2002) and Amin

\footnotetext{
${ }^{*}$ The authors are respectively from VU University Amsterdam and Tinbergen Institute; and VU University Amsterdam and Netherlands Central Bank (DNB). A previous version of this paper has circulated under the title 'Explaining Hedge Fund Strategies by Loss Aversion'. The authors thank Emmanuel Acar, Cees Dert, Chris Gilbert, Frank van den Berg, Marno Verbeek, Jenke ter Horst, an anonymous referee, and participants of the European Investment Review 2nd annual conference, EFMA meeting 2003 and EFA 2003, for helpful comments and suggestions. They thank Ting Wang for computational assistance. Siegmann acknowledges financial support from the Dutch National Science Foundation (NWO). (Paper received December 2004, revised version accepted May 2007. Online publication August 2007)
}

Address for correspondence: Arjen Siegmann, VU University Amsterdam, The Netherlands. e-mail: asiegmann@feweb.vu.nl 
and Kat (2003). Moreover, several authors have tried to attribute hedge fund returns to dynamic strategies and found that hedge fund returns typically have significant negative loadings on put option returns, see Fung and Hsieh (1997), Mitchell and Pulvino (2001), Agarwal and Naik (2004) and Amin and Kat (2003). This underlines that hedge fund returns exhibit large downside risks compared to traditional asset categories such as stocks and bonds.

A direct consequence of the large downside risk component in hedge fund returns is that the use of variance as a risk measure might be misleading. For example, Goetzmann, Ingersoll Jr., Spiegel and Welch (2002) show that a hedge fund manager can exploit the symmetric nature of the variance metric, artificially boosting his Sharpe ratio by generating payoffs that resemble those of writing put options. Hence, it is a good idea to explicitly account for the downside risks in hedge fund returns by using a downside risk measure.

In this paper, we focus on 'expected shortfall' as a risk measure. Expected shortfall puts a linear penalty on returns below a reference point. This measure is directly related to the idea of loss aversion, as formulated by Kahneman and Tversky (1979), and is conceptually straightforward. It has been used before by, for example, Benartzi and Thaler (1995), Barberis and Huang (2001), Barberis et al. (2001) and Siegmann and Lucas (2005). Expected shortfall overcomes some of the drawbacks associated with the use of Value-at-Risk, see Dert and Oldenkamp (2000), Basak and Shapiro (2001) and Vorst (2000). It is also closely related to Conditional VaR, or CVaR, see Artzner et al. (1999) and Rockafellar and Uryasev (2002). Both measures account for the event of a large loss, as well as its extent. The main difference between CVaR and our expected shortfall measure is the specification of the benchmark return level. Whereas CVaR measures the 'expected shortfall' below a quantile of the return distribution, expected shortfall as used here measures shortfall relative to a fixed return level.

Although expected shortfall has theoretically desirable properties and seems adequate for portfolio optimization involving hedge funds, the main message of the current paper is that the resulting optimal portfolios may have less desirable skewness and kurtosis properties than optimal mean-variance portfolios. Our contribution in this paper is twofold. First, we empirically investigate the sources of the above result. We find that the expected-shortfall risk measure favors payoff distributions with substantially smaller probabilities of modest amounts of shortfall, even if these distributions exhibit a more extreme left tail behavior than mean-variance portfolios. Our second contribution is theoretical. We analytically derive optimal portfolios for a mean-shortfall investor if the set of available assets includes an option. We find that mean-shortfall optimizers may prefer short put positions that are even more extreme than those of mean-variance investors, compare Goetzmann et al. (2002). We test the robustness of our results by introducing a quadratic penalty on shortfall in the analysis. Quadratic shortfall yields much more desirable skewness and kurtosis characteristics than both variance and shortfall-based optimal portfolios.

The paper is organized as follows. In Section 2, we present the data and corroborate the negative skewness of hedge fund returns. Moreover, we perform an analysis similar to Agarwal and Naik (2004) to check whether our hedge fund returns load negatively on put option returns, thus signaling a potential peso problem. In Section 3, we empirically derive optimal portfolios for mean-variance and mean-shortfall investors and compare the higher order moments of the resulting return distributions. Section 4 presents portfolio results for simulated hedge fund returns, while Section 5 provides 
the analytical results for mean-shortfall investors who can select both stocks and options in their portfolio. In Section 6 we study the effect of a quadratic penalty on shortfall. Section 7 concludes. The Appendix gathers the proofs of the results in Section 5.

\section{PROPERTIES OF MONTHLY HEDGE FUND RETURNS}

In our current paper we use well-known hedge fund style return data from the HFR data base. Our sample is from January 1994 to December 2004. Existing research has shown that hedge fund returns are highly non-normal, see for example, Brooks and Kat (2002). In particular, they are characterized by a high degree of excess kurtosis and negative skewness. The lower panel in Table 1 provides some descriptive statistics for our sample of hedge fund returns. The results corroborate those of earlier studies. Hedge fund returns are almost invariably fat-tailed with positive excess kurtosis. Moreover, more than half of the indices presented show a significant negative skewness, whereas skewness is never significantly positive.

As mentioned in the Introduction, the descriptive statistics in the lower panel of Table 1 have led to a concern about the applicability of standard variance-based risk and performance measures for portfolios with hedge funds. For example, Goetzmann et al. (2002) show that the portfolio with optimal Sharpe ratio mimics a strongly negatively skewed, short put return. Relatedly, Mitchell and Pulvino (2001) and Agarwal and Naik (2004) show that hedge fund returns load negatively on at-the-money put option returns in Sharpe style regressions. Also Amin and Kat (2003) relate hedge fund returns to option pay-offs to illustrate some of the pitfalls in a mean-variance analysis involving hedge funds.

To illustrate the extent to which our current data set displays similar features, we carry out the style analysis of Agarwal and Naik (2004). We regress the returns of the hedge fund indices on a number of standard style factors reflecting bond and stock market returns. In addition, we include the return on an at-the-money put (ATMPUT) factor. Option factors have proved to be relevant in, for example, Glosten and Jagannathan (1994), Agarwal and Naik (2004) and Fung and Hsieh (1997). Our ATMPUT factor represents the returns on an option strategy that buys an at-the-money option seven weeks before expiration, and sells it three weeks later. The options are valued using the standard Black-Scholes formula using the VIX index for the volatility.

The style factors as well as their descriptive statistics are presented in the upper panel of Table 1. It is clear that the degree of excess kurtosis and negative skewness for the stock and bond return factors is generally much lower than that of the hedge fund style indices. The highest skewness statistics are generated by the ATMPUT factor, followed by the S\&P 500 return. The regression results of the hedge fund styles on the factors are presented in Table 2.

The results in Table 2 confirm the findings of Agarwal and Naik (2004). Six out of the fourteen hedge fund styles have a ( $5 \%$ one-sided) significant negative loading on the ATM put factor (ATMPUT). For only two out of fourteen styles, the loading is positive. This illustrates that the exposure of hedge fund returns to systematic risk factors may be non-linear. Combining this with the effects of non-linear payoffs on mean variance optimizations, see for example, Leland (1999) and Goetzmann et al. (2002), it is clear that another optimization criterion than the variance may be needed for constructing optimal portfolios with hedge funds. Also compare Amin and Kat (2003). This is the subject of the next section. 
Table 1

Descriptive Statistics

\begin{tabular}{|c|c|c|c|c|c|c|}
\hline & Mean & St.Dev. & Skew & t-test & Kurt. & t-test \\
\hline & \multicolumn{6}{|c|}{ Market Variables } \\
\hline SPX & 0.50 & 4.39 & $-0.60^{* * *}$ & -2.81 & 0.40 & 0.95 \\
\hline MSWXUS & 0.13 & 4.55 & -0.07 & -0.33 & 0.70 & 1.64 \\
\hline MSEMKF & -0.09 & 6.74 & $-0.52^{* * *}$ & -2.43 & $1.49^{* * *}$ & 3.49 \\
\hline SBWGU & 0.27 & 1.93 & 0.34 & 1.58 & 0.28 & 0.65 \\
\hline SBGC & 0.23 & 1.30 & $-0.39^{*}$ & -1.84 & $0.73^{*}$ & 1.72 \\
\hline GSCITR & 0.54 & 5.67 & 0.15 & 0.68 & 0.06 & 0.15 \\
\hline USDCWMN & -0.42 & 1.85 & 0.08 & 0.36 & -0.11 & -0.25 \\
\hline \multirow[t]{2}{*}{ ATMPUT } & -0.19 & 0.96 & $1.59^{* * *}$ & 7.44 & $2.13^{* * *}$ & 5.00 \\
\hline & \multicolumn{6}{|c|}{ HFR Indices } \\
\hline RVA & 0.48 & 0.90 & $-3.02^{* * *}$ & -14.16 & $20.99^{* * *}$ & 49.23 \\
\hline MA & 0.49 & 1.01 & $-2.55^{* * *}$ & -11.98 & $12.90^{* * *}$ & 30.24 \\
\hline DS & 0.68 & 1.64 & $-1.53^{* * *}$ & -7.20 & $7.90^{* * *}$ & 18.52 \\
\hline FI & 0.37 & 0.92 & $-1.37^{* * *}$ & -6.43 & $4.09^{* * *}$ & 9.58 \\
\hline ED & 0.79 & 1.89 & $-1.30^{* * *}$ & -6.11 & $5.25^{* * *}$ & 12.30 \\
\hline CA & 0.49 & 0.99 & $-1.10^{* * *}$ & -5.15 & $2.66^{* * *}$ & 6.23 \\
\hline EM & 0.53 & 4.32 & $-0.90^{* * *}$ & -4.21 & $4.29^{* * *}$ & 10.06 \\
\hline ENH & 0.87 & 4.16 & $-0.51^{* * *}$ & -2.40 & 0.49 & 1.16 \\
\hline FoF & 0.30 & 1.72 & -0.34 & -1.61 & $4.12^{* * *}$ & 9.67 \\
\hline Macro & 0.54 & 2.16 & 0.00 & 0.00 & 0.62 & 1.45 \\
\hline EMN & 0.34 & 0.88 & 0.11 & 0.52 & $0.76^{*}$ & 1.78 \\
\hline MT & 0.60 & 2.00 & 0.14 & 0.66 & -0.53 & -1.25 \\
\hline $\mathrm{EH}$ & 0.87 & 2.64 & 0.23 & 1.10 & $1.69^{* * *}$ & 3.95 \\
\hline SS & -0.08 & 6.41 & 0.24 & 1.14 & $1.49^{* * *}$ & 3.50 \\
\hline
\end{tabular}

Notes:

This table contains the first four moments of the monthly excess returns for selected market variables and Hedge fund Research (HFR) index-returns, for the period January 1994 to December 2004. The market variables are the S\&P 500 return (SPX), the MSCI world stock index excluding the US (MSWXUS), the Morgan-Stanley Emerging Markets index (MSEMKF), the Salomon Brothers World Government Bond index (SBWGU), the Salomon Brothers Government and Corporate Bond index (SBGC), the Goldman Sachs Commodity index (GSCITR), the Trade-weighted US-dollar index (USDCWMN), and the return on an At-The-Money Put option (ATMPUT). The hedge fund styles are Relative Value Arbitrage (RVA), Merger Arbitrage (MA), Distressed Securities (DS), Event Driven (ED), Emerging Markets (EM), Fund of Funds (FoF), Fixed Income (FI), Convertible Arbitrage (CA), Equity Hedge (EH), Short Selling (SS), Equity Market Neutral (EMN), Macro, Equity Non-Hedge (ENH), and Market Timing (MT). For the HFR style indices, the rows are in descending order of magnitude of kurtosis. The $t$ columns provide the $t$-tests for the null hypotheses of skewness and excess kurtosis equal to zero. Significance at the $10 \%, 5 \%$ and $1 \%$ level is denoted by ${ }^{*},{ }^{*}$ and ${ }^{* * *}$, respectively.

\section{OPTIMAL INVESTMENT IN HEDGE FUNDS}

The apparent non-normality and non-linear payoff structure of typical hedge fund returns shown in the previous section brings us to the main issue of this paper. A usual first step forward is to replace the variance based risk measure in the optimization criterion by a shortfall based risk measure. In this way, one would expect to obtain portfolios that have better downside risk properties than optimal mean variance portfolios in terms of negative skewness and excess kurtosis. In the current section, we investigate empirically whether this is the case using the data from Section 2. In the next sections, we further support the empirical results by a simulation experiment. We 


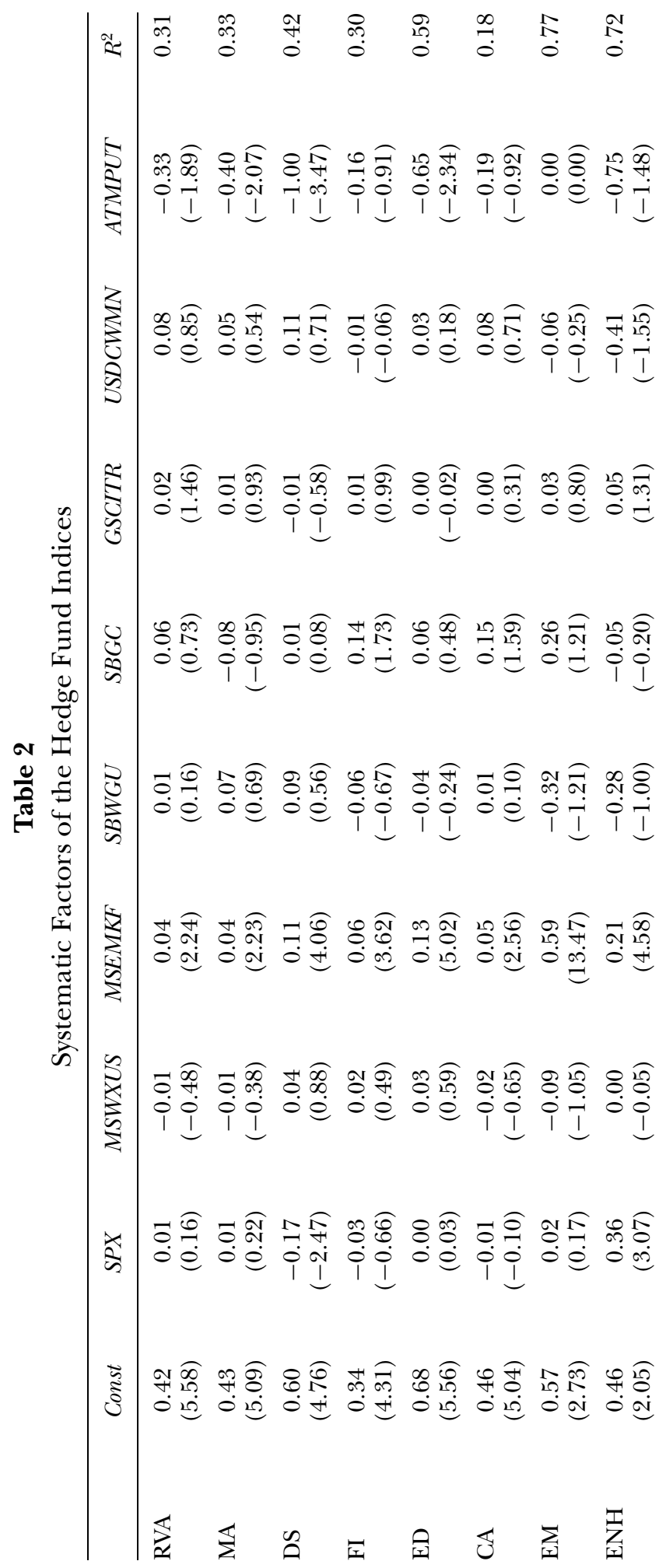







also proceed by proving analytically the effect of the inclusion of non-linear instruments in an optimal mean-shortfall framework.

\section{(i) Empirical Results}

To illustrate the key empirical results, we opt for a relatively simple set-up. We consider a static one-month investment problem for an investor who allocates his money to stocks (SPX), government bonds (SBWGU), a riskfree asset, and the hedge fund style indices presented in the lower panel of Table 1 . Let $R_{t}^{f}$ denote the riskfree rate, and $R_{t} \in \mathbb{R}^{k}$ the vector of risky returns realized in each sample month, where $k$ denotes the number of risky assets. Moreover, define $\alpha \in R^{k}$ as the weights of the risky assets in the portfolio. For a portfolio $\alpha$, the realized portfolio returns $R_{t}^{p}$ in each month are defined by:

$$
R_{t}^{p}=\alpha^{\prime} r_{t}+R_{t}^{f}
$$

for $t=1, \ldots, T$, with $r_{t}=R_{t}-R_{t}^{f}$ denoting the excess returns. To measure the realized excess returns $r_{t}$, we subtract the 90-day T-bill rate divided by three from each monthly return $R_{t}$. To account for possible survivorship biases as reported for typical hedge fund returns, see Liang (2000), we subtract an additional term of $0.21 \quad(=2.6 \%$ annually) from the excess returns $r_{t}$ for these funds.

The standard mean variance problem (MV) is given by:

$$
\begin{aligned}
& \min _{\alpha \geq 0} \quad \operatorname{Var}\left(R^{p}\right), \\
& \text { s.t. } \quad \mathrm{E}\left[R^{p}\right] \geq \mu,
\end{aligned}
$$

where $R^{p}=\alpha^{\prime} r+R^{f}$ is the return on the portfolio, E[·] denotes expectation, and $\mu$ is the expected rate of return. We assume that the distribution of the excess returns $r_{t}$ equals the empirical distribution, i.e., each of the realized excess returns is drawn with equal probability. This can be compared to a regular bootstrap procedure. Furthermore, we set the riskfree rate to the sample average of $R_{t}^{f}$, which in our case equals $0.32 \%$ (or $3.9 \%$ annually). We allow for short positions in the riskfree asset, but not in the risky assets. This seems a natural choice for the hedge fund indices, as it is generally hard or impossible to take short positions in a hedge fund. For the stock and bond indices, the restriction may be somewhat less intuitive. If we allow for short positions in stocks and bonds, however, the results presented below only change marginally and, if anything, provide even stronger support for the claims in this paper. The results for the MV optimizations are given in the MV columns in Table 3 for three levels of the required expected return $\mu=0.50,0.65,0.80$.

The results in the table show the familiar large allocations to hedge funds for MV optimal portfolios. As the required expected return $\mu$ increases, the investment in hedge funds increases further as well as the leverage factor (see $R^{f}$ row in the table). The large allocations to specific hedge funds are of course based on the fact that we optimize using ex-post, realized risk premia over the sample period. This causes the large allocations to some, and the zero allocations to other asset classes. This, however, is not the main issue of the paper. Here, we are interested in the higher moment 
Table 3

Results of the Portfolio Optimization

\begin{tabular}{|c|c|c|c|c|c|c|c|c|c|c|}
\hline & \multicolumn{6}{|c|}{ Reference Point is 0.5} & \multicolumn{4}{|c|}{ Reference Point is 0.65} \\
\hline & $M V$ & $M S F$ & $M V$ & $M S F$ & $M V$ & $M S F$ & $M V$ & $M S F$ & $M V$ & $M S F$ \\
\hline$\mu$ & 0.5 & 0.5 & 0.65 & 0.65 & 0.8 & 0.8 & 0.65 & 0.65 & 0.8 & 0.8 \\
\hline SPX & 0 & 0 & 0 & 0 & 0 & 0 & 0 & 0 & 0 & 0 \\
\hline SBWGU & 5 & 5 & 10 & 10 & 14 & 10 & 10 & 9 & 14 & 16 \\
\hline RVA & 5 & 4 & 9 & 6 & 14 & 16 & 9 & 5 & 14 & 5 \\
\hline MA & 2 & 13 & 4 & 10 & 6 & 11 & 4 & 24 & 6 & 20 \\
\hline DS & 5 & 6 & 9 & 13 & 13 & 17 & 9 & 11 & 13 & 18 \\
\hline FI & 0 & 0 & 0 & 0 & 0 & 0 & 0 & 0 & 0 & 0 \\
\hline ED & 2 & 2 & 4 & 0 & 5 & 0 & 4 & 3 & 5 & 0 \\
\hline CA & 7 & 4 & 13 & 11 & 19 & 15 & 13 & 7 & 19 & 14 \\
\hline EM & 0 & 0 & 0 & 0 & 0 & 0 & 0 & 0 & 0 & 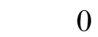 \\
\hline ENH & 0 & 0 & 0 & 0 & 0 & 0 & 0 & 0 & 0 & 0 \\
\hline FoF & 0 & 0 & 0 & 0 & 0 & 0 & 0 & 0 & 0 & 0 \\
\hline Macro & 0 & 0 & 0 & 0 & 0 & 0 & 0 & 0 & 0 & 0 \\
\hline EMN & 0 & 0 & 0 & 0 & 0 & 0 & 0 & 0 & 0 & 0 \\
\hline MT & 8 & 7 & 14 & 13 & 20 & 23 & 14 & 13 & 20 & 18 \\
\hline EH & 13 & 10 & 24 & 24 & 35 & 36 & 24 & 18 & 35 & 35 \\
\hline SS & 8 & 7 & 14 & 14 & 21 & 21 & 14 & 12 & 21 & 20 \\
\hline$R^{f}$ & 45 & 43 & -1 & -1 & -46 & -48 & -1 & -3 & -46 & -46 \\
\hline st.dev. & 0.35 & 0.36 & 0.64 & 0.64 & 0.93 & 0.94 & 0.64 & 0.66 & 0.93 & 0.94 \\
\hline sf & 0.14 & 0.13 & 0.18 & 0.18 & 0.24 & 0.23 & 0.25 & 0.25 & 0.30 & 0.29 \\
\hline skew & 0.03 & -0.56 & 0.04 & -0.09 & 0.04 & -0.00 & 0.04 & -0.57 & 0.04 & -0.13 \\
\hline kurt. & 0.04 & 1.69 & 0.04 & 0.34 & 0.04 & 0.44 & 0.04 & 1.80 & 0.04 & 0.31 \\
\hline
\end{tabular}

Notes:

This table shows the percentages invested in stocks, bonds, hedge funds and the riskfree assets, for different levels of expected returns $\mu$ and different benchmark return levels $R^{b}$. No short sales are allowed for the risky assets. The results are presented for two different risk measures: variance (MV) and expected shortfall (MSF). The asset categories are monthly returns for the S\&P500 (SPX), Salomon Brothers government bond index (SBWGU), the hedge fund styles Relative Value Arbitrage (RVA), Merger Arbitrage (MA), Distressed Securities (DS), Event Driven (ED), Emerging Markets (EM), Fund of Funds (FoF), Fixed Income (FI), Convertible Arbitrage (CA), Equity Hedge (EH), Short Selling (SS), Equity Market Neutral $(\mathrm{EMN})$, Macro, Equity Non-Hedge (ENH), Market Timing (MT), and the riskfree asset $\left(R^{f}\right)$. Finally, st.dev., sf, skew and kurt. denote the standard deviation, expected short fall below $R^{b}$, skewness and excess kurtosis of the optimal portfolio returns, respectively.

properties of the optimal portfolios and in the changes that result from a switch of the variance to shortfall as the appropriate risk measure.

A number of papers in the literature have considered the effect of downside risk measures on optimal portfolio choice, see for example, Campbell et al. (2001), Rockafellar and Uryasev (2002), Siegmann and Lucas (2005), Morton et al. (2006) and Liang and Park (2007). To account for the preference structure where the downside is penalized more heavily than the upside, a natural candidate is the mean-shortfall specification. As in Benartzi and Thaler (1995) and Siegmann and Lucas (2005), the mean-shortfall optimization problem is given by:

$$
\max _{\alpha \geq 0} \mathrm{E}\left[R^{p}\right]-\lambda \cdot \mathrm{E}\left[R^{b}-R^{p}\right]^{+},
$$


where $R^{b}$ represents the reference or benchmark return below which the shortfall is measured, and $\lambda$ is a risk aversion parameter. By varying the risk aversion parameter, the resulting optimal portfolio can take a different expected return. To make a transparent comparison with the MV framework possible, we reformulate the problem as:

$$
\begin{array}{cl}
\min _{\alpha \geq 0} & \mathrm{E}\left[R^{b}-R^{p}\right]^{+}, \\
\text {s.t. } & \mathrm{E}\left[R^{p}\right] \geq \mu .
\end{array}
$$

The advantage of the shortfall measure over the Value-at-Risk measure used in Campbell et al. (2001) is that it does not only take account of the event of shortfall, but also of the extent of shortfall. The importance of accounting also for the extent of shortfall has been demonstrated by Basak and Shapiro (2001) and Artzner et al. (1999) from different perspectives. The benchmark return $R^{b}$ could also be made dependent on the portfolio weights $\alpha$, e.g., by equating $R^{b}$ to a specific Value-at-Risk level. This would make the specification 5 coincide with the conditional Value-at-Risk framework of Rockafellar and Uryasev (2002) or the Limited-Expected-Loss results of Basak and Shapiro (2001).

The specification in 4 or 5 is the most direct way of modeling loss aversion. It assigns a penalty of $\lambda$ on every point below the reference return level $R^{b}$. In other words, an investor is more averse to returns below $R^{b}$ than he is happy with returns above $R^{b}$. Barberis et al. (2001) uses the expected shortfall measure in (7) as a risk measure in terms of wealth (rather than return) to shed light on the behavior of firm-level stock returns in an asset-pricing framework. They have a reference wealth (or return) level $W^{b}$ representing the historical benchmark wealth level, e.g., an average of recent portfolio wealth or the wealth at the end of a specific year. In the following, we assume that for the case of hedge funds, the reference point $R^{b}$ is higher than the riskfree rate: the hedge fund investor is disappointed with a return that is not above the riskfree rate. See also Shefrin and Statman (1985) who discuss the formation of reference points. We use $0.50 \%$ as a low reference point, which is around 1.5 times the riskfree rate. The high reference point equals $0.65 \%$, which is twice the riskfree rate. The results for the mean-shortfall optimizations are given in the columns labeled MSF in Tabel 3.

The results reveal that for a given expected return level $\mu$, the differences between MV and MSF in terms of portfolio weights are modest. The maximum percentage point difference in weights appear around 600 basis points, with the notable exception of merger arbitrage (MA), which shifts 20 percentage points for the high reference level $R^{b}=0.65$. The most striking results of the MSF optimizations, however, concern the riskiness of the portfolio and the higher order moments of the portfolio returns. Looking at the investments into the riskfree asset $\left(R^{f}\right)$ and into government bonds (SBWGU) we see that, if anything, investments in these assets are lower under MSF than under MV. This is a first indication that the MSF optimal portfolios may not necessarily yield a reduced risk profile in an 'intuitive' sense, despite the fact that MSF weighs the downside outcomes more heavily than the upside. Looking at the skewness and kurtosis measures of the optimal portfolio returns, we see a similar picture. The MSF portfolios are more left-skewed (or less right-skewed) than their MV counterparts. Also, the MSF portfolios reveal a higher degree of excess kurtosis. This is counter to the basic reasons for replacing the variance by shortfall. 
Table 4

Optimal Portfolios with Negatively Skewed HFR Indices

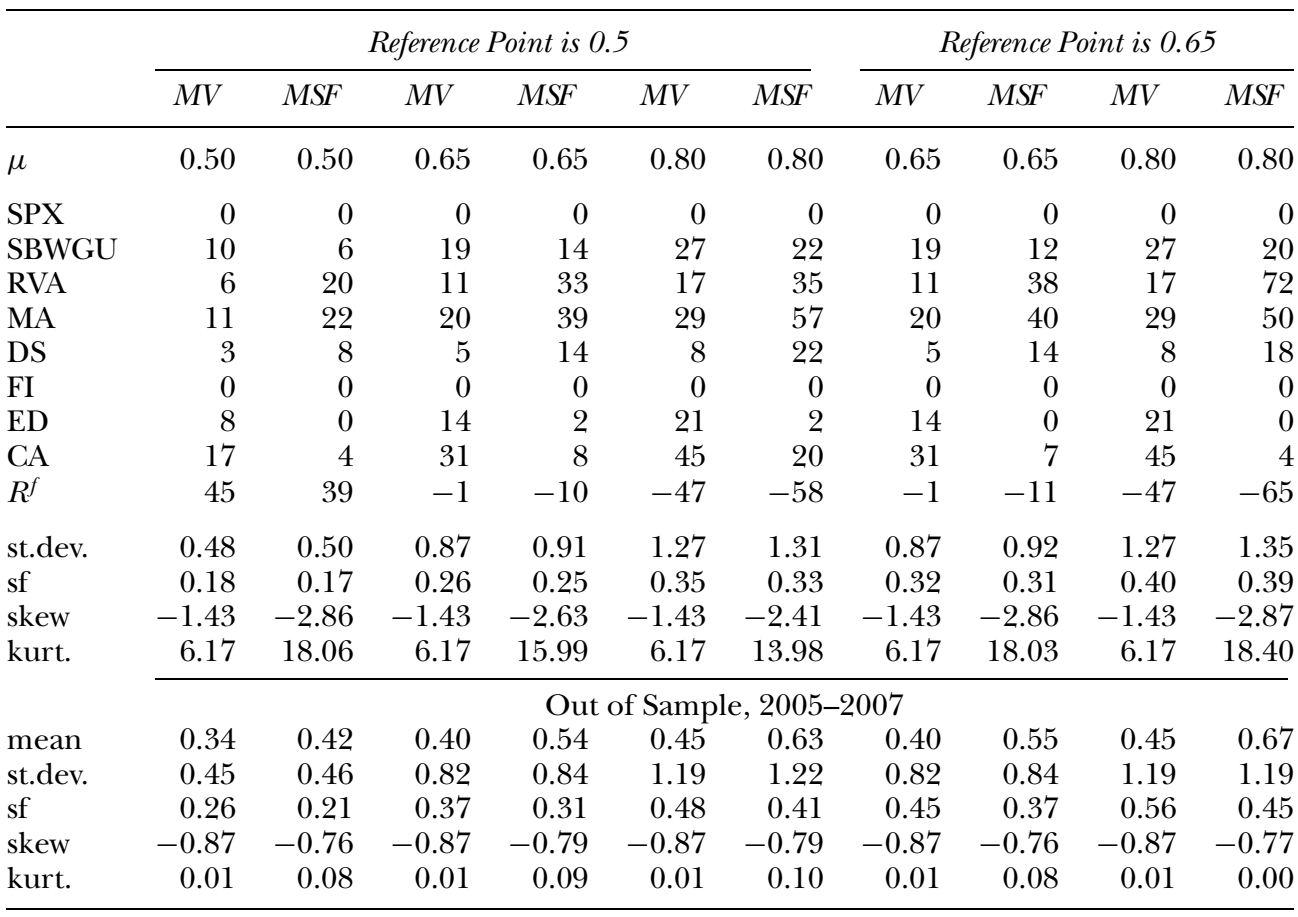

Notes:

Using only the hedge fund indices with significant negative skew, this table shows the percentages invested in stocks, bonds, hedge funds and the riskfree asset. The results are presented for different levels of expected returns $\mu$ and different benchmark return levels $R^{b}$ and two different risk measures: variance (MV) and expected shortfall (MSF). No short sales are allowed for the risky assets. The asset categories are monthly returns for the S\&P 500 (SPX), Salomon Brothers government bond index (SBWGU), the hedge fund styles Relative Value Arbitrage (RVA), Merger Arbitrage (MA), Distressed Securities (DS), Event Driven (ED), Fixed Income (FI), Convertible Arbitrage (CA), and the riskfree asset $\left(R^{f}\right)$. Finally, st.dev., sf, skew and kurt. denote the standard deviation, expected short fall below $R^{b}$, skewness and excess kurtosis of the optimal portfolio returns, respectively.

To get a better understanding of the empirical results, we re-do the analysis with only the six HFR style indices with the highest negative skewness. The results are in Table 4.

Using this restricted set of hedge fund indices, the MV portfolios again show high negative skewness and excess kurtosis. This is in line with predictions by Goetzmann et al. (2002). MV optimal portfolios should exhibit a negative skewness similar to short put positions. The previous results, however, remain robust. The negative skewness and the excess kurtosis of the MSF optimal portfolios are even higher than their MV counterparts, despite the downside risk focus of the shortfall measure. Skewness is $60-70 \%$ higher, while kurtosis is $100 \%$ higher.

To understand this outcome, we make a graph of the payoff distribution of the optimal MV and MSF portfolio returns for $\mu=0.80$ and $R^{b}=0.50$, see Figure 1 .

Figure 1 illustrates the main empirical point of this paper. The top panel shows that the MV optimal portfolio yields a return distribution that is roughly bell-shaped. 


\section{Figure 1}

Optimal Payoff Distributions Under Mean-Variance and Mean-Shortfall
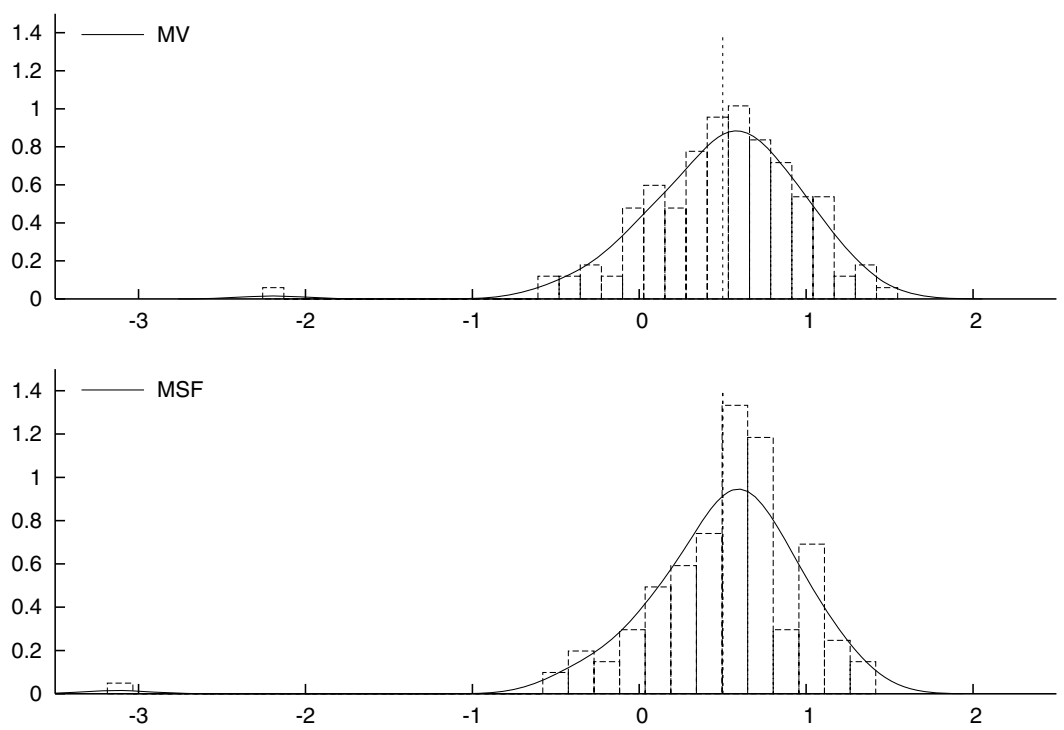

Notes:

The figure shows the resulting optimal payoffs for the optimization results in Table 4 with $\mu=0.8$ and $R^{b}=0.5$. The top panel gives the optimal mean-variance portfolio payoff distribution. The bottom panel gives the distribution for the optimal mean-shortfall portfolio. The dotted vertical line gives the level of the reference point used in the mean-shortfall optimization $\left(R^{b}=0.5\right)$. The solid density gives the kernel density estimate of the observations.

There is a point mass in the left tail at around $-2.2 \%$, corresponding to the market turmoil in 1998. The mass point reflects exactly the downside risk in hedge fund returns investors and regulators may worry about. The lower panel in Figure 1 shows the payoff under the mean-shortfall optimization. By looking at the histogram bars, it is clear that returns slightly above the reference return $R^{b}=0.5$ are much more likely than returns slightly below this benchmark. This stands in sharp contrast to the results for the MV portfolio, where this difference is absent. In addition, however, the mass point in the left tail of the MSF portfolio is now much further to the left, at $-3.1 \%$ instead of $-2.2 \%$. This explains the higher excess kurtosis and negative skewness of the MSF portfolio vis- à-vis the MV portfolio. In particular, the MSF criterion exchanges a substantial reduction in the probability of small shortfalls for an increased probability on a large shortfall. We conclude that using expected shortfall as the downside risk measure does not necessarily decrease the perceived downside risk in terms of negative skewness and excess kurtosis. This holds especially if one is worried about a potential peso problem in hedge fund returns. In such cases, expected shortfall may even make the resulting portfolio less desirable.

\section{(ii) Robustness and Out-of-Sample Performance}

For the hedge fund industry, August 1998 was a special month with large losses across hedge fund styles. Table 5 contains the descriptive statistics for the market factors and 
Table 5

Descriptive Statistics, August 1998 Removed

\begin{tabular}{|c|c|c|c|c|c|c|}
\hline & Mean & St.Dev. & Skew & t-test & Kurt. & t-test \\
\hline & \multicolumn{6}{|c|}{ Market Variables } \\
\hline SPX & 0.62 & 4.18 & $-0.39^{*}$ & -1.83 & -0.27 & -0.62 \\
\hline MSWXUS & 0.22 & 4.45 & 0.00 & 0.00 & $0.71^{*}$ & 1.67 \\
\hline MSEMKF & 0.12 & 6.31 & -0.09 & -0.43 & 0.06 & 0.14 \\
\hline SBWGU & 0.26 & 1.93 & $0.35^{*}$ & 1.66 & 0.31 & 0.72 \\
\hline SBGC & 0.22 & 1.31 & $-0.38^{*}$ & -1.78 & $0.73^{*}$ & 1.72 \\
\hline GSCITR & 0.59 & 5.66 & 0.13 & 0.62 & 0.09 & 0.20 \\
\hline USDCWMN & -0.40 & 1.85 & 0.06 & 0.29 & -0.10 & -0.23 \\
\hline \multirow[t]{2}{*}{ ATMPUT } & -0.22 & 0.89 & $1.36^{* * *}$ & 6.38 & $0.80^{*}$ & 1.86 \\
\hline & \multicolumn{6}{|c|}{ HFR Style Indices } \\
\hline FI & 0.40 & 0.86 & $-1.08^{* * *}$ & -5.06 & $3.29^{* * *}$ & 7.68 \\
\hline MA & 0.54 & 0.83 & $-0.99^{* * *}$ & -4.65 & $1.98^{* * *}$ & 4.62 \\
\hline CA & 0.52 & 0.93 & $-0.79^{* * *}$ & -3.7 & $1.63^{* * *}$ & 3.80 \\
\hline ED & 0.87 & 1.68 & -0.35 & -1.63 & 0.42 & 0.98 \\
\hline ENH & 0.99 & 3.97 & -0.29 & -1.37 & -0.15 & -0.34 \\
\hline DS & 0.75 & 1.41 & -0.16 & -0.76 & 0.55 & 1.29 \\
\hline RVA & 0.53 & 0.69 & -0.04 & -0.2 & -0.05 & -0.11 \\
\hline EM & 0.70 & 3.89 & 0.01 & 0.04 & 0.43 & 1.01 \\
\hline Macro & 0.57 & 2.12 & 0.03 & 0.14 & 0.68 & 1.60 \\
\hline SS & -0.23 & 6.22 & 0.12 & 0.55 & $1.46^{* * *}$ & 3.42 \\
\hline MT & 0.60 & 2.00 & 0.14 & 0.63 & -0.55 & -1.29 \\
\hline EMN & 0.36 & 0.86 & 0.23 & 1.07 & 0.69 & 1.62 \\
\hline FoF & 0.36 & 1.56 & $0.52^{* * *}$ & 2.44 & $1.55^{* * *}$ & 3.63 \\
\hline $\mathrm{EH}$ & 0.94 & 2.53 & $0.53^{* * *}$ & 2.46 & $1.33^{* * *}$ & 3.11 \\
\hline
\end{tabular}

Notes:

This table contains the first four moments of the monthly excess returns for selected market variables and Hedge Fund Research (HFR) index-returns, for the period January 1994 to December 2004. The market variables are the S\&P 500 return (SPX), the MSCI world stock index excluding the US (MSWXUS), the Morgan-Stanley Emerging Markets index (MSEMKF), the Salomon Brothers World Government Bond index (SBWGU), the Salomon Brothers Government and Corporate Bond index (SBGC), the Goldman Sachs Commodity index (GSCITR), the Trade-weighted US-dollar index (USDCWMN), and the return on an At-The-Money Put option (ATMPUT). The hedge fund styles are Relative Value Arbitrage (RVA), Merger Arbitrage (MA), Distressed Securities (DS), Event Driven (ED), Emerging Markets (EM), Fund of Funds (FoF), Fixed Income (FI), Convertible Arbitrage (CA), Equity Hedge (EH), Short Selling (SS), Equity Market Neutral (EMN), Macro, Equity Non-Hedge (ENH), and Market Timing (MT). For the HFR style indices, the rows are in descending order of magnitude of kurtosis. The $t$ columns provide the $t$-tests for the null hypotheses of skewness and excess kurtosis equal to zero. Significance at the $10 \%, 5 \%$ and $1 \%$ level is denoted by ${ }^{* * *}$ and ${ }^{* * *}$, respectively.

hedge fund indices when we remove this month from the return data. The apparent result of removing August 1998 from the sample is that the high (negative) skewness and kurtosis of the hedge fund indices becomes much smaller. On the one hand, this confirms the notion that skewness and kurtosis are very sensitive to outliers. On the other hand, it is difficult to see August 1998 as an outlier for investors who have actually experienced a negative return over this month. That is, August 1998 is not a result of measurement error but an actual realization of the hedge fund returns.

The portfolio results are in Table 6. It appears that the differences in risk between expected shortfall and variance become much smaller. Hence, an obvious conclusion is that the negative aspects of using expected shortfall most clearly appear for distributions 
Table 6

Optimal Portfolios with August 1998 Removed

\begin{tabular}{|c|c|c|c|c|c|c|c|c|c|c|}
\hline & \multicolumn{6}{|c|}{ Reference Point is 0.5} & \multicolumn{4}{|c|}{ Reference Point is 0.65} \\
\hline & $M V$ & $M S F$ & $M V$ & $M S F$ & $M V$ & $M S F$ & $M V$ & $M S F$ & $M V$ & $\overline{M S F}$ \\
\hline$\mu$ & 0.5 & 0.5 & 0.65 & 0.65 & 0.8 & 0.8 & 0.65 & 0.65 & 0.8 & 0.8 \\
\hline SPX & 0 & 0 & 0 & 0 & 0 & 0 & 0 & 0 & 0 & 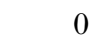 \\
\hline SBWGU & 3 & 4 & 6 & 3 & 9 & 5 & 6 & 8 & 9 & 9 \\
\hline FI & 0 & 0 & 0 & 0 & 0 & 0 & 0 & 0 & 0 & 0 \\
\hline MA & 11 & 16 & 20 & 19 & 29 & 20 & 20 & 29 & 29 & 38 \\
\hline CA & 1 & 0 & 2 & 9 & 3 & 11 & 2 & 1 & 3 & 6 \\
\hline ED & 0 & 0 & 0 & 0 & 0 & 0 & 0 & 0 & 0 & 0 \\
\hline ENH & 0 & 0 & 0 & 0 & 0 & 0 & 0 & 0 & 0 & 0 \\
\hline DS & 7 & 7 & 13 & 17 & 18 & 17 & 13 & 13 & 18 & 22 \\
\hline RVA & 18 & 12 & 32 & 18 & 47 & 37 & 32 & 23 & 47 & 27 \\
\hline EM & 0 & 0 & 0 & 0 & 0 & 0 & 0 & 0 & 0 & 0 \\
\hline Macro & 0 & 0 & 0 & 0 & 0 & 0 & 0 & 0 & 0 & 0 \\
\hline SS & 5 & 5 & 8 & 10 & 12 & 15 & 8 & 8 & 12 & 14 \\
\hline MT & 2 & 4 & 4 & 13 & 5 & 18 & 4 & 8 & 5 & 17 \\
\hline EMN & 0 & 0 & 0 & 0 & 0 & 0 & 0 & 0 & 0 & 0 \\
\hline FoF & 0 & 0 & 0 & 0 & 0 & 0 & 0 & 0 & 0 & 0 \\
\hline EH & 7 & 6 & 13 & 11 & 19 & 21 & 13 & 11 & 19 & 15 \\
\hline$R^{f}$ & 46 & 45 & 2 & 0 & -43 & -44 & 2 & 0 & -43 & -47 \\
\hline st.dev. & 0.30 & 0.30 & 0.55 & 0.57 & 0.80 & 0.82 & 0.55 & 0.56 & 0.80 & 0.81 \\
\hline sf & 0.12 & 0.12 & 0.16 & 0.16 & 0.20 & 0.20 & 0.22 & 0.22 & 0.26 & 0.25 \\
\hline skew & -0.14 & -0.26 & -0.14 & 0.04 & -0.14 & 0.11 & -0.14 & -0.26 & -0.14 & -0.12 \\
\hline kurt. & -0.24 & 0.04 & -0.24 & 0.11 & -0.24 & -0.01 & -0.24 & 0.04 & -0.24 & -0.02 \\
\hline \multicolumn{11}{|c|}{ Results for Negatively Skewed Indices } \\
\hline$\mu$ & 0.5 & 0.5 & 0.65 & 0.65 & 0.8 & 0.8 & 0.65 & 0.65 & 0.8 & 0.8 \\
\hline SPX & 0 & 0 & 0 & 0 & 0 & 0 & 0 & 0 & 0 & 0 \\
\hline SBWGU & 5 & 5 & 9 & 8 & 13 & 11 & 9 & 10 & 13 & 12 \\
\hline FI & 7 & 11 & 13 & 16 & 19 & 19 & 13 & 18 & 19 & 27 \\
\hline MA & 30 & 35 & 55 & 62 & 80 & 86 & 55 & 63 & 80 & 93 \\
\hline CA & 18 & 11 & 33 & 26 & 49 & 44 & 33 & 21 & 49 & 32 \\
\hline$R^{f}$ & 39 & 38 & -11 & -11 & -61 & -60 & -11 & -12 & -61 & -63 \\
\hline st.dev. & 0.38 & 0.38 & 0.69 & 0.70 & 1.01 & 1.01 & 0.69 & 0.70 & 1.01 & 1.02 \\
\hline sf & 0.15 & 0.15 & 0.21 & 0.21 & 0.28 & 0.27 & 0.27 & 0.27 & 0.33 & 0.33 \\
\hline skew & -0.62 & -0.74 & -0.62 & -0.71 & -0.62 & -0.68 & -0.62 & -0.73 & -0.62 & -0.74 \\
\hline kurt. & 0.42 & 0.84 & 0.42 & 0.73 & 0.42 & 0.63 & 0.42 & 0.79 & 0.42 & 0.85 \\
\hline
\end{tabular}

Notes:

This table shows the percentages invested in stocks, bonds, hedge funds and the riskfree asset. The results are presented for different levels of expected returns and different benchmark return levels $R^{b}$ and two different risk measures: variance (MV) and expected shortfall (MSF). No short sales are allowed for the risky assets. The asset categories are monthly returns for the S\&P 500 (SPX), Salomon Brothers government bond index (SBWGU), the hedge fund styles Relative Value Arbitrage (RVA), Merger Arbitrage (MA), Distressed Securities (DS), Event Driven (ED), Fixed Income (FI), Convertible Arbitrage (CA), and the riskfree asset $\left(R^{f}\right)$. Finally, st.dev., sf, skew and kurt. denote the standard deviation, expected short fall below $R^{b}$, skewness and excess kurtosis of the optimal portfolio returns, respectively. 
Table 7

Simulated Hedge Fund Returns

\begin{tabular}{rrrrr}
\hline$\Delta \mu$ & Mean & St.Dev. & Skew & Kurt. \\
\hline 0.00 & 0.50 & 1.00 & 0.00 & 0.00 \\
-2.00 & 0.50 & 1.09 & -0.26 & 0.38 \\
-4.00 & 0.50 & 1.33 & -1.17 & 2.81 \\
-6.00 & 0.50 & 1.65 & -2.07 & 5.99 \\
-8.00 & 0.50 & 2.01 & -2.70 & 8.52 \\
-10.00 & 0.50 & 2.40 & -3.10 & 10.27 \\
-12.00 & 0.50 & 2.80 & -3.37 & 11.46 \\
\hline
\end{tabular}

Notes:

This table contains the theoretical mean, standard deviation, skewness, and excess kurtosis of the return distribution from which the simulated monthly excess hedge fund returns are drawn. The return distribution is a mixture of two normals, $(1-p) \cdot \mathrm{N}\left(\mu_{1}, 1\right)+p \cdot \mathrm{N}\left(\mu_{2}, 1\right)$, with $p=0.05, \Delta \mu=\mu_{2}-\mu_{1}<$ 0 , and $(1-p) \mu_{1}+p \mu_{2}=0.5$. The shape of the return distribution is illustrated in Figure 2 .

with a sufficiently heavy left tail. If extreme crashes like August 1998 are actually present in the sample, the MSF framework appears geared toward selecting 'optimal' portfolios that are more prone to incurring large losses during such uneventful times. This result is rather ironic given the fact that shortfall is introduced for precisely the opposite reason: to limit large losses in bear markets. If, on the other hand, no crashes are present in the sample, the robustness checks reveal that difference between MSF and MV appears much more limited and, therefore, less interesting in the first place.

Besides the sensitivity to August 1998, we are also interested in the out-of-sample performance of the optimal portfolios. The lower panel in Table 4 shows the performance of the optimal portfolios from January 2005 until February 2007. As this period is not known to have monthly returns as extreme as those of August 1998, the results are as expected and show that the differences between the expected shortfall and variance-optimized portfolios are small in this case.

From the above it appears that the usefulness of expected shortfall is particularly sensitive to the precise shape of the extreme left-hand tail of the asset return distribution. If the sample at hand contains a period with a strong crash, the MSF framework appears to favor the inclusion of the assets prone to a crash. In order to analyze the influence of extreme left tail behavior on optimal MV and MSF portfolios somewhat further, we set up a small-scale simulation experiment.

\section{SIMULATION}

This section analyzes the behavior of expected shortfall as a risk measure for portfolio optimization by using a simulation experiment. In this way, we rule out the possibility that our findings thus far depend on the specific indices and exact time period of the hedge fund data used. To mimic the observed characteristics of the hedge fund data in Table 1, we simulate hedge fund returns by drawing from a mixture of two normals. With probability $1-p$, we draw from a normal with mean $\mu_{1}$ and unit variance. With probability $p$, we draw from a crash scenario, i.e., a normal with mean $\mu_{2} \ll \mu_{1}$ and unit variance. We define the magnitude of the crash as $\Delta \mu=\mu_{2}-\mu_{1}$. We fix the mean of the return distribution at 0.5 , i.e., $(1-p) \mu_{1}+p \mu_{2}=0.5$. The stock index SPX is bootstrapped from the sample observations. The number of simulation draws is set at 
Figure 2

Simulated Hedge Fund Returns
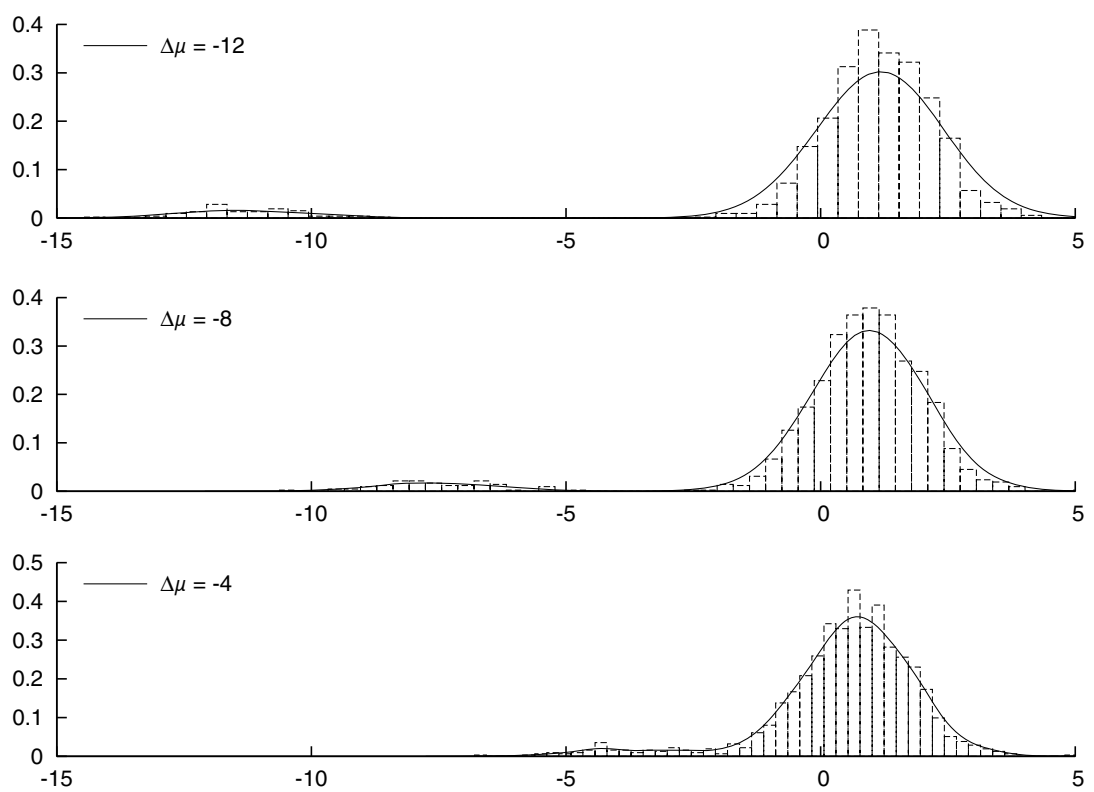

Notes:

This figure shows the pay-offs of the simulated hedge fund return. The return distribution is a mixture of two normals, $(1-p) \cdot \mathrm{N}\left(\mu_{1}, 1\right)+p \cdot \mathrm{N}\left(\mu_{2}, 1\right)$, with $p=0.05, \Delta \mu=\mu_{2}-\mu_{1}<0$, and $(1-$ p) $\mu_{1}+p \mu_{2}=0.5$. The distributions are drawn for three different values of $\Delta \mu$ and are based on 13,200 simulations (10 times the number of monthly sample observations). The panels contain the histograms of the simulations and the kernel density estimate (solid curve).

13,200 , i.e., ten times the number of monthly observations in the 11 year sample from Section 2.

The current set-up provides the most direct and transparent way to generate simulated returns with a range of different values for variance, skewness, and kurtosis. Table 7 shows the properties of the simulated distributions for different values of $\Delta \mu$, while Figure 2 shows the return distribution of the simulated hedge fund returns. The simulated returns differ from 'true' hedge fund returns in two respects. First, the simulated stock and hedge fund returns are drawn independently in our simulation experiment. This creates a diversification benefit for hedge funds. Therefore, the absolute percentage levels of hedge fund investments in the optimal portfolio are less meaningful. This, however, is not a problem for the question at hand, which concerns the higher order moments of the optimal portfolios. Second, Table 7 shows that high skewness and kurtosis coincide with high standard deviations, while the descriptive statistics of the hedge fund returns in Table 1 show that standard deviation does not clearly increase with skewness and kurtosis. However, the higher standard deviations for large values of $\Delta \mu$ only make hedge fund investments less attractive in the simulation experiment, thus re-enforcing the results we present below for the empirical setting.

With the simulated hedge fund returns and bootstrapped stock index, we perform the same optimization as in Section 3. For three values of $\Delta \mu$, Table 8 displays the optimal investment in the bootstrapped S\&P 500 and the simulated hedge fund. 
Table 8

Optimal Portfolios with Simulated Hedge Fund Returns

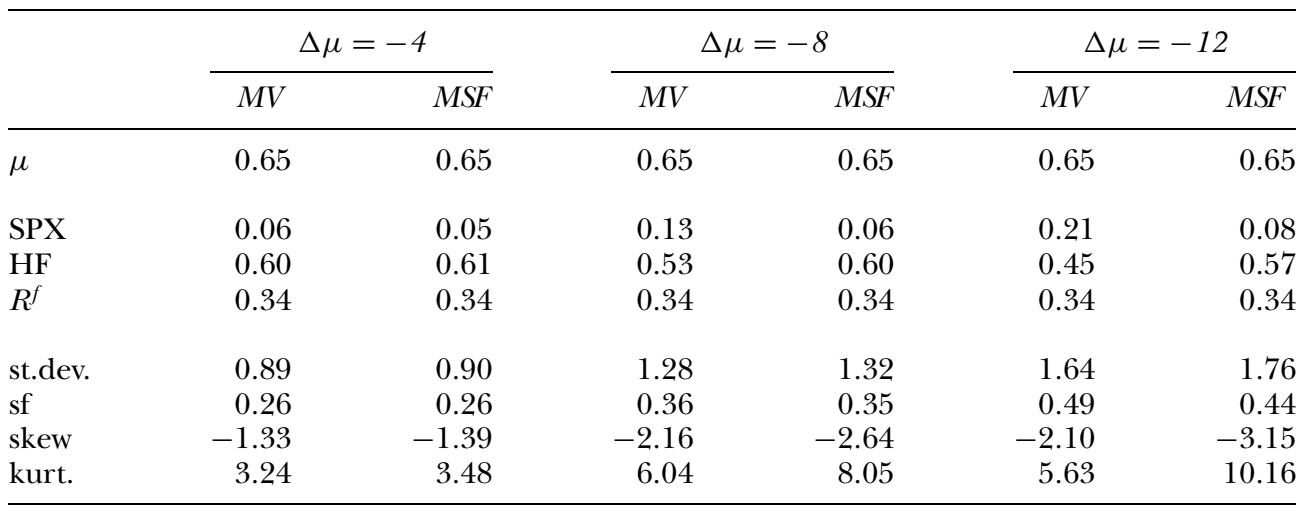

Notes:

The results are presented for the two different risk measures: variance (MV) and shortfall (MSF). The asset categories are monthly returns for the S\&P 500 (SPX), the simulated hedge fund return (HF) and the riskfree asset $\left(R^{f}\right)$. st.dev., sf, skew, and kurt. denote the standard deviation, expected short fall below $R^{b}$, skewness and excess kurtosis of the optimal portfolio returns, respectively. The reference level $R_{b}$ is set at 0.50 .

Table 8 reveals that the allocation to hedge funds for the MV portfolios decreases from $60 \%$ for $\Delta \mu=-4$ to $45 \%$ for $\Delta \mu=-12$. The optimal MSF portfolios, however, only show a reduction in the hedge fund loading from $61 \%$ down to $57 \%$. This is a difference of 13 percentage points for $\Delta \mu=-12$, where the higher loading of MSF portfolios compared to their MV counterpart is more pronounced precisely when the magnitude of the possible crash is larger. This is also illustrated by the higher order moments of the optimal portfolios in the lower panel of the table. If the magnitude of a possible crash becomes larger, the MSF optimal portfolios have a stronger negative skewness and a higher kurtosis. This is also underlined in Figure 3, which graphically displays the standard deviation, skewness and kurtosis of the optimal portfolio as a function of $\Delta \mu$. The effect of the crash magnitude on the difference in standard deviation between the optimal MV and MSF portfolios is rather mild. By contrast, the difference in skewness and kurtosis is very pronounced.

Our simulation results thus confirm the empirical results from the previous section. Although mean-shortfall gives an explicit penalty to losses, the linear character of the penalty causes it to perform worse than mean-variance if return distributions are leftskewed and fat-tailed. Again, ironically, this is precisely the situation for which the downside risk measures were introduced.

In the next section, we analyze the theoretical underpinnings of the above result by deriving analytically the optimal portfolio under MSF preferences if the investor can take a position in an asset with a highly skewed return distribution. Furthermore, in Section 6 we investigate empirically whether the above results can be off-set by considering other downside risk measures.

\section{OPTIMAL PORTFOLIOS UNDER MEAN-SHORTFALL WITH AN OPTION}

From the empirical and simulation results in the previous sections, we now turn to the derivation of the analytical underpinnings of these results. To derive the optimal portfolio analytically under MSF preferences, we resort to the specification in (4). 
Figure 3

Moments of Optimal Payoffs Using Simulated Returns
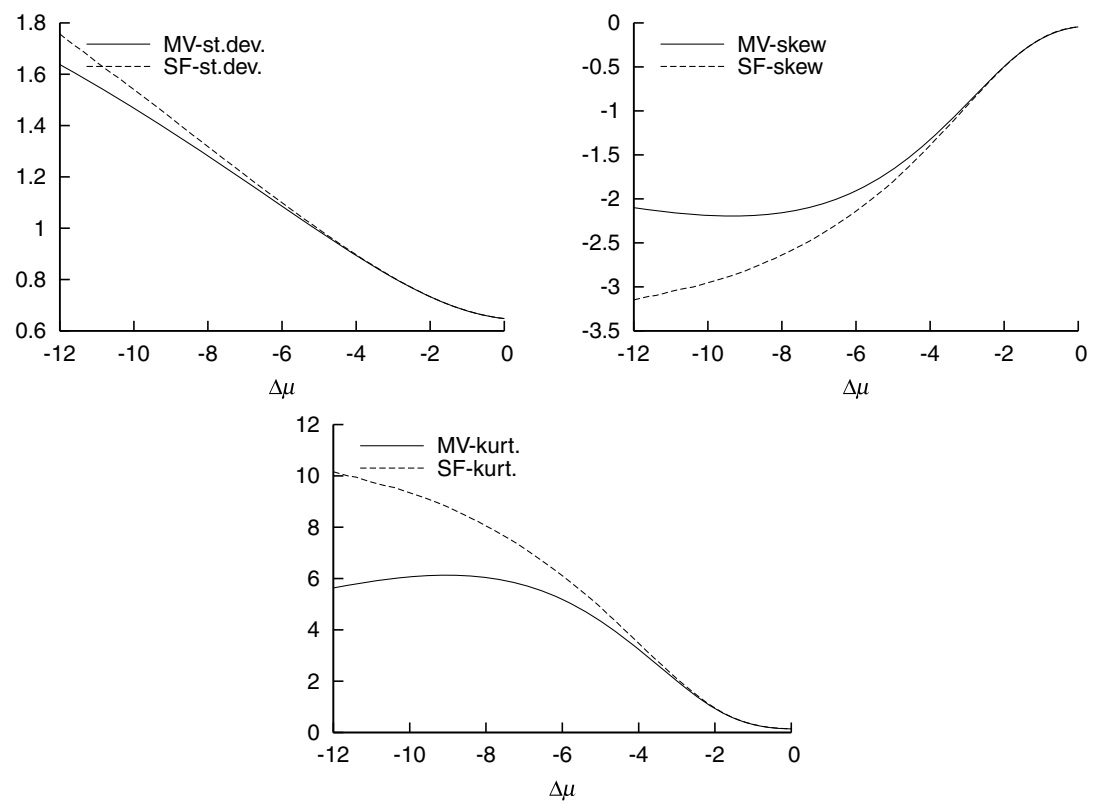

Notes:

This figure shows the standard deviation, skewness and excess kurtosis for the optimal portfolios using simulated returns. The expected portfolio return is fixed at $\mu=0.65$ and the reference point for the MSF model is $R^{b}=0.5 . \Delta \mu$ is the distance between the left-tail ('crash') observations and the main mass of the distribution, $p=0.05$ and $N=13200$.

Define $R_{1}$ as the return in the next period, and consider the mean-shortfall optimization given by:

$$
\max \mathrm{E}\left[R_{1}\right]-\lambda \cdot \mathrm{E}\left[\left(R^{b}-R_{1}\right)^{+}\right]
$$

where $\lambda$ is the loss aversion parameter.

To model the investment opportunities, we assume that the investor in (7) can select three assets, namely a risk-free asset, a linear risky asset, and an option on the risky asset. We label the risky asset as stock in the rest of this section and normalize its initial price to one. It should be kept in mind, however, that our results are not limited to stock investments. Alternative interpretations of the risky asset comprise stock indices, bonds or interest rates, and currencies. The stock has an uncertain payoff $u$ with distribution function $G(u)$. We assume that $G(\cdot)$ is defined on $(0, \infty)$, is twice continuously differentiable and satisfies $\mathrm{E}\left[u-R^{f}\right]>0$, i.e., there is a positive excess return on stocks. The option is modeled as a European call option on the stock with strike price $x$. Its current price is denoted by $c$. To avoid making a particular choice for the option's pricing model, we set the planning period equal to the option's time to maturity. The option's payoff, $R_{c}$, is now completely determined by the stock return as $(u-x)^{+}$. We assume there is a positive risk premium for the option as well, i.e., $\mathrm{E}\left[(u-x)^{+} / c\right]>R^{f}$. For simplicity, we abstain from any constraints on the investment 
process. We obtain:

$$
R_{1}=R^{f}+\alpha_{0} \cdot\left(u-R^{f}\right)+\alpha_{1} \cdot\left(R_{c}-c \cdot R^{f}\right),
$$

where $R^{f}$ is the payoff on the risk-free asset, $\alpha_{0}$ is the number of shares, and $\alpha_{1}$ the number of call options. The investor now maximizes 7 over $\left\{\alpha_{0}, \alpha_{1}\right\}$.

To solve model 7, we define the surplus variable:

$$
S_{0}=1-R^{b} / R^{f} .
$$

It gives the relative position to the reference return $R^{b}$ with respect to the risk-free return $R^{f}$. If the surplus is negative, the reference return cannot be attained by a risk-free strategy. The converse holds for a positive surplus. Barberis et al. (2001) and Barberi and Huang (2001) use the same idea of a surplus together with mental accounting practices adopted by loss averse investors. In their set-up, surplus represents the difference between the current price of a stock or fund and its historical benchmark.

The following theorem gives our main result.

Theorem 1: The optimal investment strategy for a finite solution to problem 7 is characterized as follows:

I. If the surplus $S_{0}$ is positive and the strike $x$ is larger than some $x^{p}$, then:

$$
\alpha_{0}^{*}=0, \quad \text { and } \quad \alpha_{1}^{*}=S_{0} / c,
$$

i.e., the surplus is entirely invested in the call option.

II. If the surplus $S_{0}$ is negative and the strike $x$ is smaller than some $x^{n}$, and if (through put-call parity) $p$ denotes the price of a put option with strike price $x\left(p=x / R^{f}+c-1\right)$, then:

$$
\alpha_{0}^{*}=-S_{0} / p, \quad \text { and } \quad \alpha_{1}^{*}=-\alpha_{0}^{*},
$$

i.e., the negative surplus is depleted by writing put options.

III. Otherwise:

$$
\left(\begin{array}{c}
\alpha_{0}+\alpha_{1} \\
-\alpha_{0}
\end{array}\right)=\frac{1}{A} \cdot\left(\begin{array}{c}
x-\bar{u}_{1} \\
\bar{u}_{2}-x
\end{array}\right) \cdot S_{0} \cdot R^{f},
$$

where $\bar{u}_{1}<x<\bar{u}_{2}$, and $A>0$ are defined in the Appendix.

Proof: See the Appendix.

Theorem 1 states that if ( 7 ) has a finite solution, then the optimal investment strategy takes one out of three possible forms. A finite solution is ensured by a sufficiently high loss aversion parameter $\lambda$ in (7). Strategy III is a condensed representation of either a long or short straddle ${ }^{1}$ position. As $A, x-\bar{u}_{1}$, and $\bar{u}_{2}-x$ are all positive under III, the sign of $\alpha_{0}+\alpha_{1}$ and $-\alpha_{0}$ are completely determined by the sign of the surplus $S_{0}$. If the

1 We use the term straddle to denote a portfolio of long put and call positions, where the number of puts and calls are not necessarily equal. 


\section{Figure 4}

Characteristics of the Optimal Payoffs as a Function of the Strike Price $x$ and the Reference Point $R^{b}$

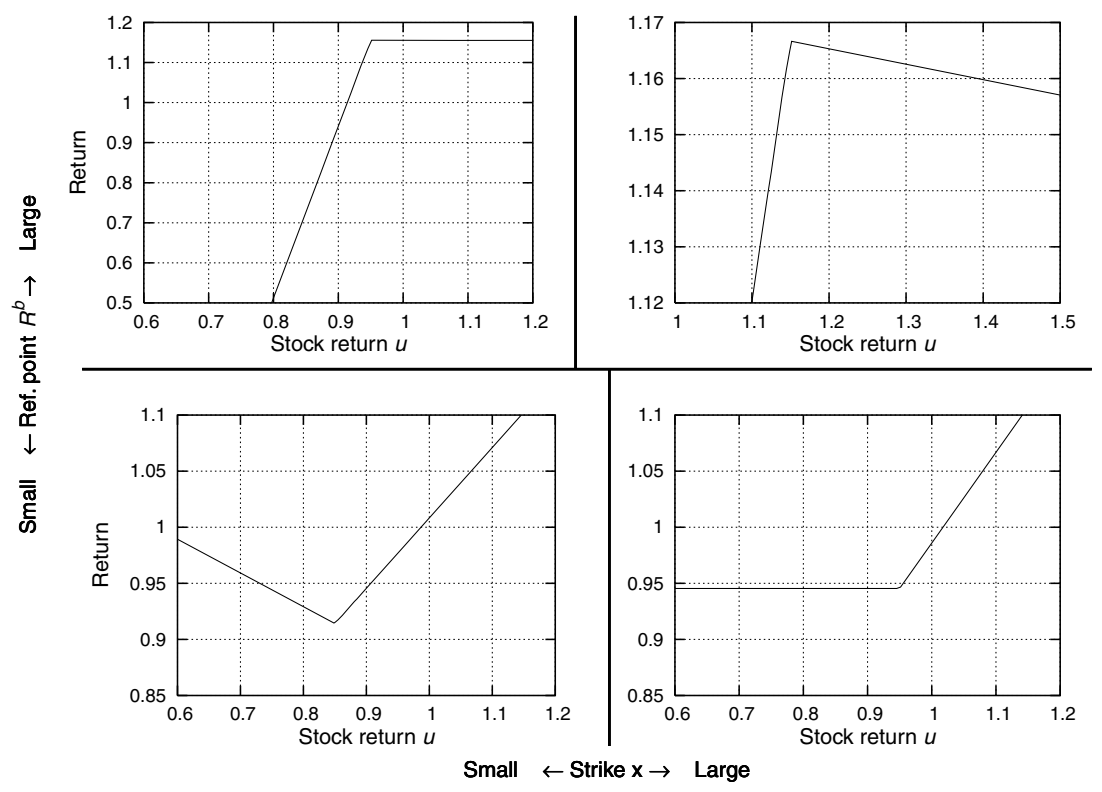

Notes:

The figure displays optimal payoffs as a function of the risky return $u$ for four different combinations of the reference point $R^{b}$ and strike price $x$ of the option. Though the precise form and steepness of these four payoffs may vary if other combinations of $R^{b}$ and strike are used, the patterns shown are representative (in terms of positive/negative slope to the left/right of the strike) for the area in which they are plotted. These areas are bounded by the bold lines in the figure. The horizontal line is the separation between $R^{b}$ lower and higher than $R^{f}$. The two vertical lines separate 'high' from 'low' strike prices (for positive and negative surplus, respectively). The lower-left panel has a strike of 0.85 , the lower-right and upper-left panel of 0.95 , the upper-right panel of 1.15 . The stock return is distributed lognormal $(0.085,0.16)$. The call is priced using Black-Scholes.

surplus is positive, we obtain a long straddle position. There is a short position in stocks, $\alpha_{0}<0$, which is offset by the long call position for sufficiently high stock prices, $\alpha_{0}+$ $\alpha_{1}>0$. Similarly, if the surplus is negative, we obtain a short straddle payoff pattern. The Appendix shows how $\bar{u}_{1}$ and $\bar{u}_{2}$ are derived from the model's parameters and defines $A$ as a function of $\bar{u}_{1}, \bar{u}_{2}$, and $R^{f}$ only.

With solution III having two different payoffs associated with it, we find that a total of four different payoffs can be optimal for the model in (7). Figure 4 illustrates the result, presenting the optimal payoffs resulting from a numerical optimization for a chosen set of parameters. For a positive surplus, i.e., a low reference point, either a long straddle or a long call strategy is optimal (bottom graphs), depending on whether the strike price is low or high (left-hand vs. right-hand plot), respectively. For negative surpluses, i.e., high benchmark returns $R^{b}$, the short put and short straddle are optimal. Strike prices and surplus levels determine which of the payoffs is optimal in a particular setting.

It can be seen from Theorem 1 that a higher absolute value of $R^{b} / R^{f}$ leads to more 'aggressive' investment policies, i.e., larger investments in the risky asset. For example, 
for smaller values of the reference point $R^{b}$ below $R^{f}$, the number of long straddles or long puts increases, resulting in a steeper payoff over the non-flat segments of the payoff pattern. A similar result holds if the reference return becomes increasingly higher than $R^{f}$. The strike price is a control variable that can be regarded as representing the availability of options, or a choice variable representing the preference for a particular dynamic strategy. The following corollary contains a useful result on the choice of this strategy.

Corollary 1: In a surplus situation $\left(R^{b}<R^{f}\right)$, the long-call payoff pattern is preferred. In a shortfall situation $\left(R^{b}>R^{f}\right)$, the short-put payoff pattern is preferred.

Proof: See the Appendix.

Corollary 1 shows that if the strike $x$ can be freely chosen, the upper-right and lowerleft pattern in Figure 4 are the preferred patterns for a surplus and shortfall situation, respectively. As outlined in Section 3, in the context of hedge funds it is natural to assume that $R^{b}>R_{f}$, given the higher risk of hedge funds compared to the riskfree investment. Thus, Corollary 1 gives the analytical support for the preference of MSF investors for short put payoffs, which explains the empirical results and simulation evidence of the previous sections. In particular, looking more closely at the proof of Corollary 1, we see that larger (short) positions in options at lower strike prices are preferred. This is in accordance with the empirical results from the previous section, where the mass point in the left tail shifts to the left under MSF preferences. In short, both the theoretical and empirical results point in the same direction. Using a linear downside risk measure such as shortfall results in payoff distributions that may show undesirable left-tail behavior.

\section{OTHER DOWNSIDE RISK MEASURES}

Given the negative skewness and excess kurtosis properties of optimal MSF portfolios, it is interesting to see whether these properties extend to optimal portfolios based on other downside risk measures. In particular, we consider a quadratic downside risk measure that penalizes large extents of shortfall more than linearly. Consider the following optimization problem:

$$
\begin{array}{rl}
\min _{\alpha \geq 0} & \mathrm{E}\left[\left(\left[R^{b}-R^{p}\right]^{+}\right)^{2}\right], \\
\text { s.t. } & \mathrm{E}\left[R^{p}\right] \geq \mu .
\end{array}
$$

The risk measure in (13) is called quadratic shortfall or downside deviation. The results of the optimization problem are presented in Table 9.

The results are strikingly different compared to Table 4 . When using the quadratic shortfall measure, some of the hedge fund loadings change substantially. This holds in particular for Merger Arbitrage (MA) and Relative Value Arbitrage (RVA), which are the $\mathrm{HF}$ indices with the highest kurtosis. In addition, also some of the conventional asset classes have a substantially different loading, see the bonds (SBWGU) and riskfree $\left(R^{f}\right)$ asset. The increased loading on bonds and riskfree are suggestive that the portfolio will have a reduced risk profile in an intuitive sense. This is evident if we turn to the higher order moments of the portfolio. Whereas the skewness of the optimal MSF portfolio was about twice the size of its MV counterpart, the (negative) skewness of the MQSF 
Table 9

Comparison with Mean-Quadratic Shortfall (MQSF)

\begin{tabular}{|c|c|c|c|c|c|c|}
\hline & \multicolumn{3}{|c|}{ Reference Point is 0.5} & \multicolumn{3}{|c|}{ Reference Point is 0.65} \\
\hline & $M V$ & $M S F$ & $\overline{M Q S F}$ & $M V$ & $M S F$ & $M Q S F$ \\
\hline$\mu$ & 0.65 & 0.65 & 0.65 & 0.65 & 0.65 & 0.65 \\
\hline SPX & 0 & 0 & 0 & 0 & 0 & \\
\hline SBWGU & 19 & 14 & 27 & 19 & 12 & 25 \\
\hline RVA & 11 & 33 & 0 & 11 & 38 & \\
\hline MA & 20 & 39 & 5 & 20 & 40 & \\
\hline DS & 5 & 14 & 6 & 5 & 14 & 8 \\
\hline ED & 14 & 2 & 21 & 14 & 0 & 19 \\
\hline FI & 0 & 0 & 0 & 0 & 0 & 0 \\
\hline CA & 31 & 8 & 33 & 31 & 7 & 33 \\
\hline$R^{f}$ & -1 & -10 & 8 & -1 & -11 & 6 \\
\hline st.dev. & 0.87 & 0.91 & 0.90 & 0.87 & 0.92 & 0.89 \\
\hline sf & 0.26 & 0.25 & 0.28 & 0.32 & 0.31 & 0.34 \\
\hline skew & -1.43 & -2.63 & -0.59 & -1.43 & -2.86 & -0.70 \\
\hline kurt. & 6.17 & 15.99 & 1.64 & 6.17 & 18.03 & 2.18 \\
\hline
\end{tabular}

Notes:

This table shows the percentages invested in stocks, bonds, hedge funds and the riskfree asset, for an expected return level of $\mu=0.65$ and two levels of the benchmark return $R^{b}$. The results are presented for the three different risk measures: variance (MV), shortfall (MSF), and quadratic shortfall (MQSF). The asset categories are monthly returns for the S\&P 500 (SPX), Salomon Brothers government bond index (SBWGU), the hedge fund styles Relative Value Arbitrage (RVA), Merger Arbitrage (MA), Distressed Securities (DS), Event Driven (ED), Fixed Income (FI), Convertible Arbitrage (CA), and the riskfree asset $\left(R^{f}\right)$. Finally, st.dev., sf, skew and kurt. denote the standard deviation, expected short fall below $R^{b}$, skewness, and excess kurtosis of the optimal portfolio returns, respectively.

portfolio is only about half the size of that of the MV portfolio. Similarly, the kurtosis coefficients of the MQSF portfolios are about a third of the kurtosis of the MV portfolio.

\section{CONCLUSIONS AND DISCUSSION}

In this paper we have shown the potential pitfalls of using expected shortfall as a risk measure in the context of hedge fund investing and optimal portfolio construction. Compared with mean-variance (MV), the optimal portfolios under mean-shortfall (MSF) perform worse in terms of skewness and kurtosis. The return distribution of the optimal MSF portfolio reveals that the mean-shortfall criterion may substantially reduce the probability of small shortfalls at the expense of an increased extreme (left) tail mass. This is an important result for investors that consider using expected shortfall as a risk measure when evaluating the returns to a portfolio involving hedge funds. Despite the fact that shortfall penalizes larger extents of shortfall more heavily than modest shortfall, one should be careful in using it in a portfolio optimization context.

These empirical results are supported by our analytical results. In the context of MV, Goetzmann et al. (2002) offers an explanation of the (possible) misplaced attractiveness of hedge funds: if investors optimize Sharpe ratios, then the optimal payoffs resembles those of a short-put strategy. Similarly, we show that if investors have MSF preferences 
and a benchmark or desired return level above the riskfree rate, the optimal MSF portfolio will also exhibit high negative skewness and short put payoff patterns as in Goetzmann et al. (2002). This is empirically relevant, as several hedge funds load negatively on put option returns in style regressions, as shown in the earlier literature and in Section 2 of this paper. The problems of the MV framework for hedge fund selection and optimal portfolio construction thus appear not easily solved by simply replacing the variance by expected shortfall as a risk measure. Given our computations in the last part of the paper, replacing the variance by a quadratic shortfall measure (MQSF) appears much more promising in this respect, even though quadratic shortfall is not a coherent risk measure in the sense of Artzner et al. (1999).

Though our prime focus in this paper has been on hedge fund investments, the general drawbacks of expected shortfall as a risk measure in portfolio optimization also extend to other asset classes with similar possible extreme tail behavior. Finally, one could also interpret our results as yet another motivation for the apparent attractiveness of hedge funds in the investment industry. A recent paper by Agarwal et al. (2007) finds significant risk premia for higher-order moments in hedge fund returns. It is quite possible that investors still have difficulties in assessing their own preferences for higher-moment risk, as illustrated by the results in this paper.

\section{APPENDIX}

\section{Proof of Theorem 1}

We start by restating the optimization problem in (7) as:

$$
\begin{gathered}
\max _{\alpha_{0}, \alpha_{1}} V\left(\alpha_{0}, \alpha_{1}\right), \\
\text { with } V\left(\alpha_{0}, \alpha_{1}\right)=\mathrm{E}\left[R_{1}\right]-\lambda \cdot \mathrm{E}\left[\left(R^{b}-R_{1}\right)^{+}\right],
\end{gathered}
$$

subject to:

$$
R_{1}=R^{f}+\alpha_{0} \cdot\left(u-R^{f}\right)+\alpha_{1} \cdot\left(R_{c}-c \cdot R^{f}\right) .
$$

Define $p=x / R^{f}+c-1$, the price of the put option corresponding to the price of the call following from put-call parity, see e.g., Hull (1997). Define $R_{c, x, G(\cdot)}$ as the expected return on the call option with strike $x$ on an asset with return $u \sim G(\cdot)$, given by $\mathrm{E}\left[(u-x)^{+} / c\right]$. For ease of notation, we drop the subscripts $x$ and $G(\cdot)$. Likewise, we denote the expected return on the put option with $R^{p}$. To ensure a finite optimal solution we need the following assumptions:

A: $\lambda R^{f} G(x)>R_{c}-R^{f}$,

B: $\lambda \int_{0}^{x}(x-u)^{+} / p-R^{f} d G>-\left(R^{p}-R^{f}\right)$,

$\mathrm{C}: R_{c}$ is increasing in $x$.

The motivation for these two assumptions will follow from the proofs below. In short, assumptions $\mathrm{A}$ and $\mathrm{B}$ put a lower bound on the loss aversion parameter $\lambda$ to ensure that the trade-off between risk and return leads to a finite solution. Assumption $\mathrm{C}$ is tested empirically in Coval and Shumway (2001), who find that the expected return of S\&P index option returns increases with the strike price. 
There are four possible payoff patterns resulting from the combination of a risk-free asset, a stock, and a call option on the stock, namely decreasing-decreasing (I), increasing-increasing(II), decreasing-increasing(III), increasing-decreasing(IV), where for example case (I) refers to a setting where the payoff increases in $u$ both before and after the strike price $x$.

\section{Pattern I (decreasing-decreasing)}

Conditions for case I are $\alpha_{0} \leq 0$ and $\alpha_{0}+\alpha_{1} \leq 0$. The first order conditions in this case are given by:

$$
\frac{\partial V}{\partial \alpha_{0}}=0 \Rightarrow 0=\mathrm{E}\left[u-R^{f}\right]+\lambda \int_{\bar{u}}^{\infty}\left(u-R^{f}\right) d G,
$$

and

$$
\frac{\partial V}{\partial \alpha_{1}}=0 \Rightarrow 0=\mathrm{E}\left[(u-x)^{+}-c \cdot R^{f}\right]+\lambda \int_{\bar{u}}^{\infty}\left([u-x]^{+}-c \cdot R^{f}\right) d G,
$$

where $\bar{u}$ is a constant depending on $\left(\alpha_{0}, \alpha_{1}\right)$. Using $\mathrm{E}[u]>R^{f}$ and $\mathrm{E}\left[(u-x)^{+}\right]>c$. $R^{f}$, we obtain that the right-hand sides of both (A4) and (A5) are positive for any value of $\bar{u}$, such that there is no interior optimum. The solution in situation I is, therefore, to set $\alpha_{0}^{*}=\alpha_{1}^{*}=0$.

\section{Pattern II (increasing-increasing)}

Conditions for case II are $\alpha_{0}>0$ and $\alpha_{0}+\alpha_{1}>0$. First order conditions are given by the system:

$$
\left\{\begin{array}{l}
\mathrm{E}\left[u-R^{f}\right]+\lambda \int_{0}^{\bar{u}}\left(u-R^{f}\right) d G=0 \\
\mathrm{E}\left[(u-x)^{+}-c \cdot R^{f}\right]+\lambda \int_{0}^{\bar{u}}\left([u-x]^{+}-c \cdot R^{f}\right) d G=0
\end{array}\right.
$$

where $\bar{u}$ is again a constant depending on $\left(\alpha_{0}, \alpha_{1}\right)$. Each equation in (A6) has either zero or two solutions. The zero-solution case for the first order condition corresponds to unbounded solutions for the original optimization problem (A1), since the left-hand side in (A6) must then necessarily be positive. We have abstracted from unbounded solutions however. Since the integrands in the two equations of (A6) are different, the two equations will not be satisfied for the same value of $\bar{u}$. Hence, the optimum is attained at the extremals. In this case, for II the extremals are defined by two sets of parameter values, given by:

$$
\alpha_{0}=0, \quad \alpha_{1}>0
$$

or

$$
\alpha_{0}>0, \quad \alpha_{0}+\alpha_{1}=0 .
$$

Starting with the former, investing only in the call option implies an optimization problem with the following first order condition for an interior optimum:

$$
\mathrm{E}\left[(u-x)^{+}-c \cdot R^{f}\right]+\lambda \int_{0}^{\bar{u}}\left([u-x]^{+}-c \cdot R^{f}\right) d G=0,
$$


where $\bar{u}=\left(R^{b}-R^{f}\right) / \alpha_{1}+x+c \cdot R^{f}$. By definition, $\bar{u} \geq x$. Under assumption $\mathrm{A}$, we find that the FOC is never fulfilled, i.e. the derivative with respect to $\alpha_{1}$ is negative. Without an interior optimum, the optimal solution is given by:

$$
\alpha_{1}^{*}= \begin{cases}\left(1-R^{b} / R^{f}\right) / c & \text { if } R^{f}>R^{b}, \\ 0 & \text { if } R^{f} \leq R^{b} .\end{cases}
$$

We call this the long call strategy.

Now for the second case of extremals in situation I:

Define $\alpha_{2}=\alpha_{0}+\alpha_{1}$, and $p=\left(x+c \cdot R^{f}-R^{f}\right) / R^{f}$. Condition for an interior optimum is:

$$
\mathrm{E}\left[(x-u)^{+}-p \cdot R^{f}\right]+\lambda \int_{0}^{\bar{u}}\left([x-u]^{+}-p \cdot R^{f}\right) d G=0,
$$

where $\bar{u}=\left(R^{f}-R^{b}\right) / \alpha_{2}+x-p \cdot R^{f}$. By definition, $\bar{u} \leq x$. Under assumption $\mathrm{B}$, the FOC has no solution, i.e. the derivative with respect to $\alpha_{2}$ is positive.

Without an interior optimum, the optimal solution is given by:

$$
\alpha_{2}^{*}= \begin{cases}\left(R^{b} / R^{f}-1\right) / p & \text { if } R_{B}>R^{f} \\ 0 & \text { if } R^{b} \leq R^{f}\end{cases}
$$

We call this the short put strategy.

For $R^{b} \leq R^{f}$ the long call strategy has a higher objective value than the short put. This is seen from the objective values, which are $R^{f}+\left(1-R^{b} / R^{f}\right)\left(R_{c}-R^{f}\right)$ for the long call versus the short put value of $R^{f}$.

For $R^{b}>R^{f}$ the short put strategy has higher objective value than the long call. This is seen from the objective values, which are $R^{f}+\lambda \cdot\left(R^{f}-R^{b}\right)$ for the long call versus the short put value that is larger than $R^{f}+\lambda \cdot\left(R^{f}-R^{b}\right) \cdot G(x)$. The last inequality follows from Assumption B.

\section{Pattern III (decreasing-increasing: straddle)}

Situation III is characterized by $\alpha_{0}<0, \alpha_{0}+\alpha_{1}>0$.

The two values for which $R_{1}=R^{b}$ are given by $\bar{u}_{1}<x$ and $\bar{u}_{2}>x$. They are defined as:

$$
\begin{aligned}
& \bar{u}_{1}=\frac{R^{b}-R^{f}-\alpha_{0} \cdot R^{f}-\alpha_{1} \cdot c \cdot r f}{\alpha_{0}} \\
& \bar{u}_{2}=\frac{R^{b}-R^{f}-\alpha_{0} \cdot R^{f}-\alpha_{1} \cdot x-\alpha_{1} \cdot c \cdot r f}{\alpha_{0}+\alpha_{1}} .
\end{aligned}
$$

The first order conditions are given by:

$$
\begin{gathered}
\frac{\partial V}{\partial \alpha_{0}}=\mathrm{E}\left[u-R^{f}\right]+\lambda \cdot \int_{\bar{u}_{1}}^{\bar{u}_{2}}\left(u-R^{f}\right) d G=0, \\
\frac{\partial V}{\partial \alpha_{1}}=\mathrm{E}\left[(u-x)^{+}-c \cdot R^{f}\right]+\lambda \cdot \int_{\bar{u}_{1}}^{\bar{u}_{2}}\left([u-x]^{+}-c \cdot R^{f}\right) d G=0 .
\end{gathered}
$$




$$
\text { s.t. } \bar{u}_{1}<x<\bar{u}_{2} \text {. }
$$

It can be checked that under the current assumptions the Hessian is negative definite. If the FOC is fulfilled for a feasible $\left(\alpha_{0}, \alpha_{1}\right)$, it constitutes a local optimum. Note that if the FOC is satisfied, the value of the objective function can be written as:

$$
R^{f}+\lambda \cdot R^{f} \cdot\left(1-R^{b} / R^{f}\right) \cdot\left(G\left(\bar{u}_{2}^{*}\right)-G\left(\bar{u}_{1}^{*}\right)\right) \leq R^{f}+\lambda \cdot S_{0} .
$$

The function value of the optimum in situation II for positive surplus is given by the value of the long call strategy as:

$$
R^{f}+\left(1-R^{b} / R^{f}\right) \cdot \mathrm{E}\left[(u-x)^{+} / c-R^{f}\right]=R^{f}+S_{0} \cdot\left[R_{c}-R^{f}\right] .
$$

Using assumption $\mathrm{C}$, which says that $R_{c}-R^{f}$ is increasing in $x$, we find that for $x \rightarrow 0$ and $S_{0}>0$ the straddle payoff is better than the long call payoff of case II.

\section{Pattern IV (increasing-decreasing: short straddle)}

Situation IV is similar to case III and characterized by $\alpha_{0}>0, \alpha_{0}+\alpha_{1}<0 . \bar{u}_{1}$ and $\bar{u}_{2}$ are the same as in situation III.

The first order conditions are given by:

$$
\begin{aligned}
\frac{\partial V}{\partial \alpha_{0}}= & \mathrm{E}\left[u-R^{f}\right]+\lambda \cdot \int_{0}^{\bar{u}_{1}}\left(u-R^{f}\right) d G+\lambda \cdot \int_{\bar{u}_{2}}^{\infty}\left(u-R^{f}\right) d G \\
\frac{\partial V}{\partial \alpha_{1}}= & \mathrm{E}\left[(u-x)^{+}-c \cdot R^{f}\right]+\lambda \cdot \int_{0}^{\bar{u}_{1}}\left((u-x)^{+}-c \cdot R^{f}\right) d G \\
& +\lambda \cdot \int_{\bar{u}_{2}}^{\infty}\left((u-x)^{+}-c \cdot R^{f}\right) d G .
\end{aligned}
$$

Again, it can be checked that Hessian is negative definite. If the FOC is fulfilled for a feasible $\left(\alpha_{0}, \alpha_{1}\right)$, it constitutes a local optimum. Note that if the FOC is satisfied, the value of the objective function can be written as:

$$
R^{f}+\lambda \cdot\left(R^{f}-R^{b}\right) \cdot\left(1-\left(G\left(\bar{u}_{2}^{*}\right)-G\left(\bar{u}_{1}^{*}\right)\right)\right) .
$$

The function value of the optimum in situation II for negative surplus is given by the short put strategy as:

$$
\begin{aligned}
& R^{f}+\alpha_{2} \cdot p \cdot\left(\mathrm{E}\left[R^{p}-R^{f}\right]+\lambda \cdot \int_{0}^{x}(x-u)^{+}-p \cdot R^{f} d G\right) \\
& \quad+\lambda \cdot\left(R^{f}-R^{b}\right) \cdot G(x),
\end{aligned}
$$

which is, according to assumption $\mathrm{B}$, larger than:

$$
R^{f}+\lambda \cdot\left(R^{f}-R^{b}\right) \cdot G(x)
$$

This implies that there is a strike $y$ such that for strikes $x<y$, the short put strategy of pattern II has a higher objective value than the current short-straddle pattern IV. 
Having found the optimal payoffs for each pair $\left(x, S_{0}\right)$, we end with defining $A$ in Theorem 1. From the definition of $\bar{u}_{1}$ and $\bar{u}_{2}$ in (A13) and (A14), we can write $\alpha_{0}$ and $\alpha_{1}$ as a function of $\bar{u}_{1}$ and $\bar{u}_{2}$ in the following way:

$$
\left(\begin{array}{c}
\alpha_{0}+\alpha_{1} \\
-\alpha_{0}
\end{array}\right)=\frac{1}{A} \cdot\left(\begin{array}{c}
x-\bar{u}_{1} \\
\bar{u}_{2}-x
\end{array}\right) \cdot S \cdot R^{f},
$$

where $A=-\left(\bar{u}_{2}-x\right)\left(x-\bar{u}_{1}\right)+c R^{f}\left(x-\bar{u}_{1}\right)+\left(\bar{u}_{2}-x\right) p R^{f}$, and $p R^{f}=x+c R^{f}-$ $R^{f}$. As the long straddle payoff is only optimal for positive surplus, we find $A>0$. This concludes the proof.

\section{REFERENCES}

Agarwal, V. and N.Y. Naik (2004), 'Risks and Portfolio Decisions Involving Hedge Funds', The Review of Financial Studies, Vol. 17, No. 1, pp. 63-98.

- , G. Bakshi and J. Huij (2007), 'Higher-moment Equity Risk and the Cross-section of Hedge Fund Returns', Working Paper.

Amin, G. and H. Kat (2003), 'Hedge Fund Performance 1990-2000: Do the Money Machines Really Add Value?', Journal of Financial and Quantitative Analysis, Vol. 38, No. 2, pp. 251-74.

Artzner, P., F. Delbaen, J.-M. Eber and D. Heath (1999), 'Coherent Measures of Risk', Mathematical Finance, Vol. 9, No. 3, pp. 203-28.

Barberis, N. and M. Huang (2001), 'Mental Accounting, Loss Aversion, and Individual Stock Returns', Journal of Finance, Vol. 56, No. 4, pp. 1247-92.

- $\longrightarrow$ and T. Santos (2001), 'Prospect Theory and Asset Prices', Quarterly Journal of Economics, Vol. 66, No. 1, pp. 1-53.

Basak, S. and A. Shapiro (2001), 'Value-at-Risk-Based Risk Management: Optimal Policies and Asset Prices', Review of Financial Studies, Vol. 14, No. 2, pp. 371-405.

Benartzi, S. and R.H. Thaler (1995), 'Myopic Loss Aversion and the Equity Premium Puzzle', Quarterly Journal of Economics, Vol. 110, pp. 73-92.

Brooks, C. and H. Kat (2002), 'The Statistical Properties of Hedge Fund Index Returns and Their Implications for Investors', Journal of Alternative Investments, Vol. 5, No. 2, pp. 25-44.

Brown, S.J., W.N. Goetzmann and R. G. Ibbotson (1999), 'Offshore Hedge Funds: Survival and Performance, 1989-95', Journal of Business, Vol. 72, No. 1, pp. 91-117. and J. Park (1997), 'Conditions for Survival: Changing Risk and the Performance of Hedge Fund Managers and CTAs', Unpublished Manuscript (Yale University).

Campbell, R., R. Huisman and K. Koedijk (2001), 'Optimal Portfolio Selection in a Value-atRisk Framework', Journal of Banking and Finance, Vol. 25, No. 9, pp. 1789-804.

Coval, J.D. and T. Shumway (2001), 'Expected Option Returns', Journal of Finance, Vol. 54, No. 3, pp. 983-1009.

Dert, C. and B. Oldenkamp (2000), 'Optimal Guaranteed Return Portfolios and the Casino Effect', Operations Research, Vol. 48, No. 5, pp. 768-75.

Fung, W. and D.A. Hsieh (1997), 'Empirical Characteristics of Dynamic Trading Strategies: The Case of Hedge Funds', Review of Financial Studies, Vol. 10, No. 2, pp. 275-302.

Glosten, L. and R. Jagannathan (1994), 'A Contingent Claim Approach to Performance Evaluation', Journal of Empirical Finance, Vol. 1, pp. 133-60.

Goetzmann, W.N., J. Ingersoll Jr., M. Spiegel and I. Welch (2002), 'Sharpening Sharpe Ratios', NBER Working Paper 9116.

Hull, J. C. (1997), Options, Futures, and Other Derivatives (Prentice-Hall Inc.).

Kahneman, D. and A. Tversky (1979) 'Prospect Theory: An Analysis of Decision Under Risk', Econometrica 47, pp. 263-91.

Leland, H.E. (1999), 'Beyond Mean-Variance: Risk and Performance Measurement in a Nonsymmetrical World', Financial Analysts Journal, Vol. 55, No. 1, pp. 27-36.

Liang, B. (2000), 'Hedge Funds: The Living and the Dead', The Journal of Financial and Quantitative Analysis, Vol. 35, No. 3, pp. 309-26. 
Liang, B. and H. Park (2007), 'Risk Measures for Hedge Funds: A Cross-Sectional Approach', European Financial Management, Vol. 13, No. 2, pp. 333-70.

Mitchell, M. and T. Pulvino (2001), 'Characteristics of Risk and Return in Risk Arbitrage', Journal of Finance, Vol. 56, No. 6, pp. 2135-75.

Morton, D., E. Popova and I. Popova (2006), 'Efficient Fund of Hedge Funds Construction Under Downside Risk Measures', Journal of Banking and Finance, Vol. 30, No. 2, pp. 503-18.

Rockafellar, T.R. and S. Uryasev (2002), 'Conditional Value-at-Risk for General Loss Distributions', Journal of Banking and Finance, Vol. 26, No. 7, pp. 1443-71.

Shefrin, H. and M, Statman (1985), 'The Disposition to Sell Winners Too Early and Ride Losers Too Long: Theory and Evidence', Journal of Finance, Vol. 40, No. 3, pp. 777-90.

Siegmann, A.H. and A. Lucas (2005), 'Discrete-Time Financial Planning Models Under LossAverse Preferences', Operations Research, Vol. 53, No. 3, pp. 403-14.

Vorst, T. (2000), 'Optimal Portfolios under a Value at Risk Constraint', Proceedings of the European Congress of Mathematics (Barcelona, July), pp. 10-14. 